\title{
Onko kanapunkin torjuntaan vaihtoehtoja?
}

Tuomo Tuovinen ja Bengt Lindqvist

MTT Kasvintuotannon tutkimus, 31600 Jokioinen, tuomo.tuovinen@mtt.fi, bengt.lindqvist@mtt.fi

\section{Tiivistelmä}

Kanapunkki (Dermanyssus gallinae) on globaali loinen, jonka merkitys munivien kanojen verta imevänä ulkoloisena on kasvussa. Kanapunkki aiheuttaa kanoissa anemiaa, levottomuutta ja aggressiivisuutta ja heikentää munintatulosta. Kanapunkki voi myös levittää tauteja kanoihin.

Kanapunkin torjunnassa on pyrittävä estämään punkkien leviäminen kanalaan kanojen, tarvikkeiden, ihmisten ja eläinten mukana. Ennaltaehkäisevien torjuntakeinojen lisäksi kanapunkin torjuntaa varten on mm. Englannissa tutkittu lukuisten kasviperäisten eteeristen öljyjen vaikutuksia kanapunkkiin ja tulokset ovat olleet lupaavia. Kanapunkin kemialliseen torjuntaan on käytettävissä foksiimia tehoaineena sisältävä valmiste, jonka käyttö edellyttää eläinlääkärin määräystä. Valmisteen käyttö on tällä hetkellä mahdollista myös kanojen munintajakson aikana.

Tutkimukset petopunkkien mahdollisesta käytöstä kanapunkkien biologisessa torjunnassa alettiin tutkia MTT:lla vuonna 2007 ja vuosina 2008-2009 tehtiin kaksi torjuntakoetta Hypoaspis spp. petopunkkeja käyttäen. Tavoitteena on kehittää vaihtoehtoinen, kemiallista ja fysikaalista torjuntaa täydentävä biologisen torjunnan menetelmä osana kanapunkin integroitua torjuntaa. Biologisen torjunnan ohessa on myös tehty kokeita foksiimia tehoaineena sisältävällä valmisteella ja havainnoitu kanalan kuumailmakäsittelyn pitkäaikaisvaikutusta kanapunkkipopulaatioon.

Kanapunkin torjuntaan v. 2008 hyväksytty foksiimi-valmiste oli tehokas ja vaikutus kesti useita kuukausia. Valmisteen etuna on mahdollisuus käyttää sitä kanojen ollessa kanalassa. Kanalan kuumailmakäsittelyllä kanapunkki saatiin täysin hävitettyä. Käsittelyn lopullinen hyöty riippuu siitä voidaanko kanapunkkien kulkeutuminen kanalaan estää ja kuinka pitkään.

Biologisen torjunnan kokeiden perusteella arvioimme, että Hypoaspis spp. petopunkit ovat lupaavia kanapunkin torjuntaeliöitä. Seuraavaksi tulisi kehittää käytännössä toimivaa sovellusta. Kevään 2009 kokeissa toisena petolajina käytetty karvajalkapetopunkki (Hypoaspis aculeifer) on mahdollisesti tehokkaampi kuin harsosääskipetopunkki (Hyposaspis miles) kanalassa vallitsevissa olosuhteissa.

\section{Asiasanat}

Kanapunkki, Dermanyssus gallinae, kanojen hyvinvointi, integroitu torjunta, kemiallinen torjunta, biologinen torjunta, petopunkit, Hypoaspis spp. 


\section{Johdanto}

Kanapunkin (Dermanyssus gallinae) merkitys munivien kanojen verta imevänä ulkoloisena on kasvussa. Kanapunkki on globaali loinen joka esiintyy kaikkialla missä kanojakin. Euroopassa kanapunkki esiintyy yleisimmin lattiakanaloissa, mutta se on yleistymässä myös virikehäkeissä ja tavallisissa häkkikanaloissa (Sparagano ym. 2009). Kanapunkki aiheuttaa kanoissa anemiaa, levottomuutta ja aggressiivisuutta ja heikentää munintatulosta. Ääritapauksissa loisinta johtaa kanojen kuolemaan. Lisäksi kanapunkki voi levittää eläintauteja, myös salmonellaa (Valiente Moro ym. 2007).

Kanapunkin perustorjuntana on tärkeintä pyrkiä estämään punkkien leviäminen kanalaan kanojen, erilaisten tarvikkeiden kuten kierrätettävien munakennojen sekä ihmisten ja eläinten mukana. Kanalarakennuksessa ei saisi sallia lainkaan lintujen pesintää, sillä kanapunkkia löytyy mm. kottaraisten, varpusten ja kyyhkyjen pesistä. Hyvä hygienia ja säännöllinen siivous, imurointi ja desinfioiva pesu auttavat kanapunkkien määrän pitämisessä pienenä, vaikka näiden toimenpiteiden vaikutus on lyhytaikainen.

Ennaltaehkäisevien torjuntakeinojen lisäksi kanapunkin torjuntaa varten on mm. Englannissa tutkittu lukuisten kasviperäisten eteeristen öljyjen vaikutuksia (MITEeHEN 2009). Sadan prosentin kuolleisuus laboratorio-oloissa vuorokauden aikana saavutettiin öljyillä, joita oli uutettu tarhaajuruohosta (Thymus), valkosipulista (Allium), mausteneilikasta (Syzygium), laventelista (Lavendula), sitruunaheinästä (Cymbopogon), mintuista (Mentha), eukalyptuksesta (Eucalyptus), ruusumyrtistä (Leptospermum), männystä (Pinus) ja katajasta (Juniperus). Tulosten pohjalta tutkijaryhmä toivoo voivansa kehittää uusia torjuntamenetelmiä. Paitsi kuolleisuutta lisäävää vaikutusta kasviperäisillä valmisteilla on myös karkottavia vaikutuksia.

Kanapunkin kemialliseen torjuntaan on Euroopassa vuodesta 2007 alkaen ja nyt myös Suomessa käytettävissä orgaanista fosforiyhdistettä foksiimia tehoaineena sisältävä valmiste BayMite (ByeMite) (Evira 2009). Foksiimia on aikaisemmin käytetty varastotuholaisten torjuntaan ja se oli suosittu torjunta-aine pitkään kestävän vaikutuksensa vuoksi. Valmisteen käyttö kanalassa edellyttää eläinlääkärin määräystä. Kanapunkille voi kehittyä resistenssiä orgaanisia fosforivalmisteita vastaan jos käyttö yleistyy (Roy ym. 2009). Uutena torjuntavalmisteena on esitelty Neem-puun (Azadirachta indica) siemenistä uutettua atsadiraktiinia tehoaineena sisältävä valmiste (Abdel-Ghaffar ym. 2008). Atsadiraktiini on Euroopassa hyväksytty käytettäväksi monien viljelykasvien tuholaisten torjuntaan.

Biologista torjuntaa kanapunkin luontaisia vihollisia käyttäen on vasta äskettäin alettu tutkia, ensimmäisenä on liikkeelle lähdetty Suomessa (Tuovinen 2008, Lesna ym. 2009).

MTT:n koekanalassa aloitettiin vuonna 2007 tutkimukset maaperässä luontaisesti elävien petopunkkien käyttömahdollisuuksista kanapunkin torjuntaan (Tuovinen ym. 2009). Lisäksi olemme tutkineet BayMite-valmisteen tehoa kanapunkkiin (Tuovinen ym. 2008). Vuonna 2008 toteutettiin lisäksi koekanalan perusteellinen desinfiointi 70-80 asteen kuumailmakäsittelyllä kolmen vuorokauden ajan. MTT:n tutkimusten tavoitteena on kehittää vaihtoehtoinen, kemiallista ja fysikaalista torjuntaa täydentävä biologisen torjunnan menetelmä kanapunkin integroidun torjunnan osana.

\section{Aineisto ja menetelmät}

Petopunkkien käyttöä kanapunkkien torjuntaan tutkittiin MTT:n virikehäkkikanalassa kahdessa kokeessa vuosina 2008-2009. Kokeiden välillä kanalassa käytettiin BayMite-valmistetta ja kokeiden päätyttyä kanalssa tehtiin perusteellinen kuumailmakäsittely. Petopunkkien levityksessä lähdettiin oletuksesta että ne eivät muodosta itseuudistuvaa kantaa kanalaan vaan että levityksiä on toistettava säännööisin väliajoin.

Ensimmäisessä kokeessa loka-joulukuussa 2008 torjuntaan käytettiin harsosääskipetopunkkeja (Hypoaspis miles), joiden oli laboratoriokokeissa todettu mielellään syövän kanapunkin nuoruusasteita (Tuovinen \& Lindqvist 2007). Petopunkit hankittiin Biotus Oy:stä, joka kasvattaa niitä käytettäväksi harsosääskien ja ripsiäisten torjuntaan kasvihuonevihanneksilla. Petopunkit toimitettiin turveseoksessa paperipusseissa (1000 kpl/pussi, yksi pussi 16 kanaa kohti), joissa olevista rei’istä petopunkit vähitellen siirtyivät ulos pussissa olevan ravinnon loppuessa. Pussit sijoitettiin häkkien kattona olevien peltilevyjen päälle. Pareittain asetetut pussit saivat olla paikoillaan kaksi viikkoa ja viikoittain vaihdettiin yksi uusi pussi tilalle. Näin käsiteltyjen häkkien väliin jätettiin pussittomat häkit samassa yhtenäisessä häkkirivissä. Kanapunkkien runsaudenvaihtelua seurattiin häkkeihin asetetuilla aaltopahvipyydyksillä, jotka vaihdettiin viikoittain (Nordenfors \& Chirico 2001). 
Toisessa kokeessa käytettiin kahta petopunkkilajia, harsosääskipetopunkin lisäksi kokeeseen otettiin karvajalkapetopunkki (Hypoaspis aculeifer), jonka myös tiedetään saalistavan kanapunkkeja (Lesna ym. 2009). Käsittelyt tehtiin samassa häkkirivissä kuin ensimmäinen koe edllisenä syksynä. Käsittelyjärjestys oli seuraava: harsosääskipetopunkki - käsittelemätön - karvajalkapetopunkki käsittelemätön jne., yhteensä neljänä toistona. Petopunkkien levitys aloitettiin helmikuun alussa paperipusseissa, $1000 \mathrm{kpl} / 16$ kanaa, häkkien katolle noin kahden viikon välein helmikuusta huhtikuun loppuun jonka jälkeen tehtiin vielä yksi levitys toukokuun lopulla. Petopunkkien levitys lopetettiin kuusi viikkoa ennen kanalan tyhjentämistä, jotta voitaisiin todeta miten petopunkkilevityksen lopettaminen vaikutti kanapunkkien määrään. Kanapunkkien määrän kehittymistä seurattiin viikoittain kunnes kanala tyhjennettiin heinäkuussa 2009, jonka jälkeen kanalassa tehtiin kuumailmakäsittely.

\section{Tulokset ja tulosten tarkastelu}

Syksyn 2008 torjuntakokeessa kanapunkkien määrä oli kohtalaisen suuri, viikon kuluttua aloituksesta 27 aktiivista punkkia pyydystä kohti. Välihäkeissä, joiden katolle petopunkkeja ei suoraan levitetty, määrä oli keskimäärin alle 3,3 kpl/pyydys. Petopunkkilevitysten jatkuessa viikoittain kanapunkkien määrä putosi noin kolmannekseen, kunnes alkoi kuukauden kuluttua nopeasti nousta (kuva 1). Välihäkeissä määrä pysyi tällöinkin pienenä. Koe lopetettiin perusteelliseen puhdistukseen ja BayMite-käsittelyyn ennen joulukuun puoliväliä.

Koska harsosääskipetopunkki käyttää ravinnokseen lähinnä varhaisilla toukka-asteilla olevia kanapunkkeja, oli runsaan kanapunkkimäärän vähentäminen niille ylivoimainen tehtävä joissakin kerranteissa. Välihäkeissä kanapunkkien pieni määrä viittasi siihen, että petopunkit siirtyivät useita metrejä häkkirivistössä ja saattoivat harventaa kanapunkkikantaa koko häkkirivissä.

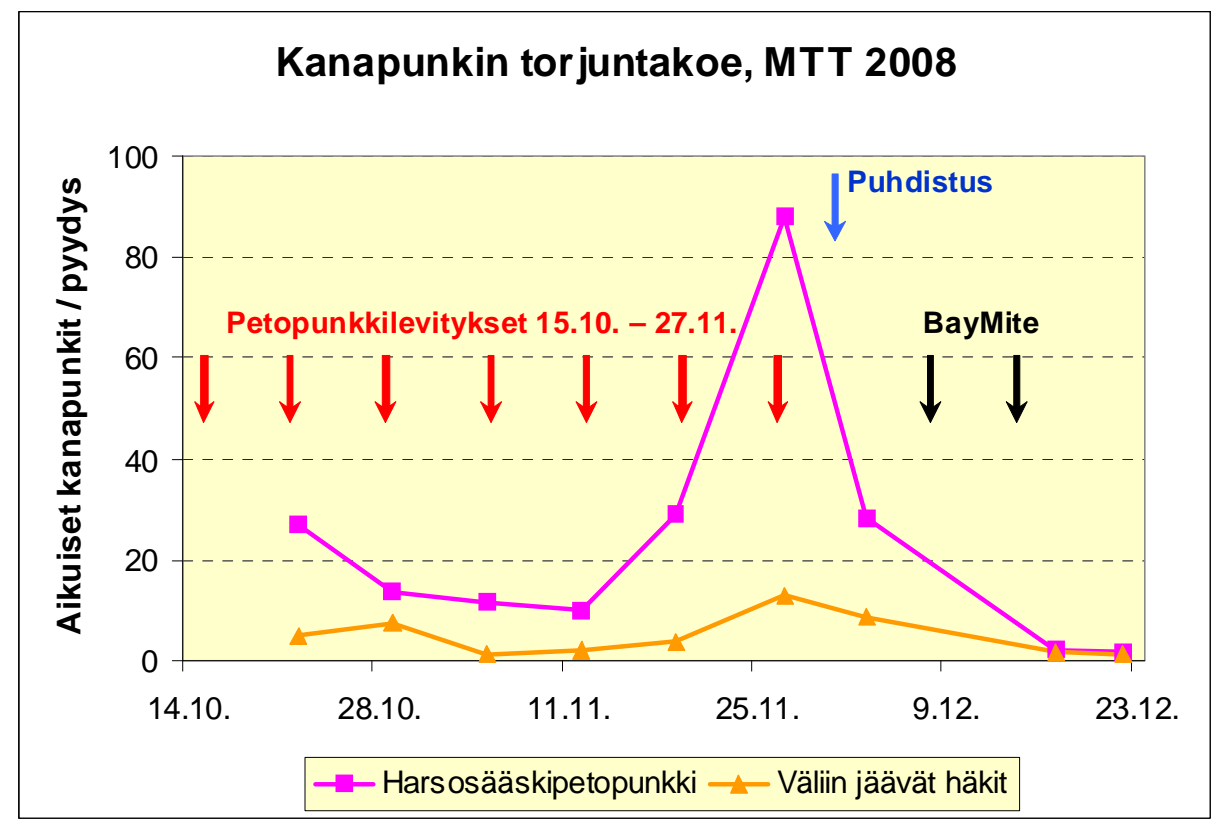

Kuva 1. Kanapunkin torjuntakokeessa syksyllä 2008 käytettiin harsosääskipetopunkkia ja levitykset tehtiin viikoittain. Kokeen jälkeen tehtiin perusteellinen puhdistus ja sen jälkeen BayMite käsittelyt.

Joulukuussa 2008 kanapunkkien määrä oli BayMite-käsittelyn jälkeen 1,4 kpl/pyydys. BayMite valmisteen vaikutus oli aikaisemmassa kokeessa kestänyt jopa 3 kuukautta, joten vielä tammihelmikuussa 2009 käsittelyt todennäköisesti pitivät kanapunkkien määrän pienenä. Kevään 2009 koe aloitettiin kuitenkin jo helmikuun alussa, koska oletuksena oli että kanapunkkien määrän tulee olla torjunnan alkaessa hyvin pieni. Kanapunkkien määrä pysyi koko kevään ajan hyvin alhaisena niin kauan kuin petopunkkien levitystä jatkettiin (Kuva 2). Neljän viikon väli petopunkkien levityksessä ei vielä aiheuttanut merkittävää kanapunkkien määrän nousua, mutta jo kahden viikon kuluttua levitysten lopettamisesta kanapunkkimäärä kasvoi jo moninkertaiseksi. 


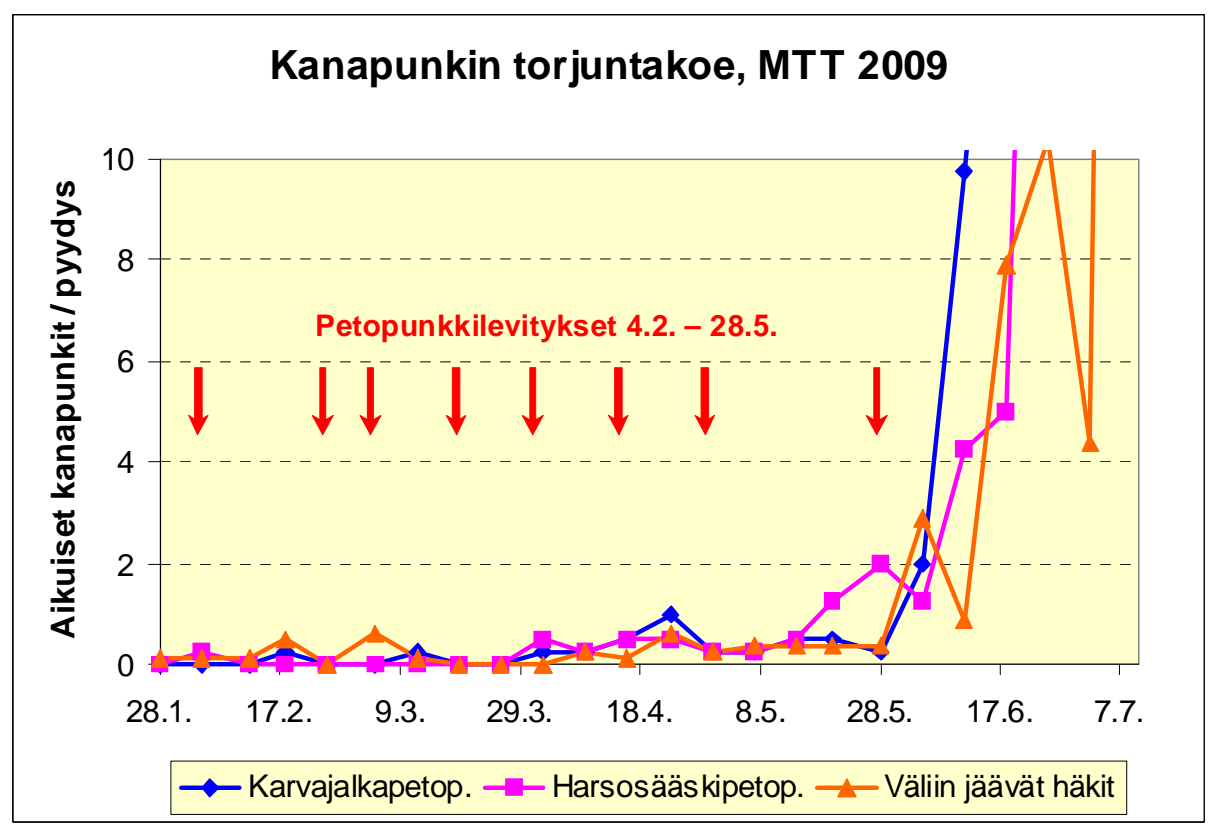

Kuva 2. Kanapunkin torjuntakokeessa keväällä 2009 käytettiin sekä harsosääskipetopunkkia että karvajalkapetopunkkia. Levitykset tehtiin noin kahden viikon välein. Kanala tyhjennettiin kanoista 10.7 .

Kanapunkkikannan nopea kasvu heti petopunkkien levityksen loputtua osoitti, että petopunkit eivät muodostaneet pysyvää kantaa kanalaan, vaan torjuntatulos oli täysin riippuvainen jatkuvasta levityksest. Kanalassa vallinnut noin 50 \%:n suhteellinen kosteus ei ehkä ollut riittävä Hypoaspispetopunkkien munien kehittymiseen, jolloin petopunkkikanta ei päässyt uudistumaan.

Kanalassa tehtiin kokeen päätyttyä heinäkuun puolivälissä perusteellinen puhdistus ja lämpökäsittely lämminilmapuhaltimilla kolmen päivän ajan 70-80 asteessa. Kuumailmakäsittely hävitti kaikki kanapunkit myös kanalan rakenteista eikä vielä marraskuun alkuun mennessä uutta saastuntaa ollut tapahtunut.

\section{Johtopäätökset}

Kanapunkin torjuntaan hyväksytyllä BayMite-valmisteella on tehokas ja pitkäaikainen vaikutus. Valmisteen käyttö on ainakin toistaiseksi sallittua myös kanojen ollessa häkeissä, kunhan huolehditaan siitä että ruiskute ei osu suoraan kanoihin. Mikäli valmisteen käyttö yleistyy, on odotettavissa että resistenttejä kanapunkkikantoja kehittyy ennen pitkää, jolloin torjunta jälleen vaikeutuu. Kasviperäisistä valmisteista odotetaan kemiallisen torjunnan korvaajia, mutta kehitystyö on vasta alussa, mahdollisesti lukuun ottamatta atsadirakteeni-valmisteita.

Kanalan kokonaisvaltaisen kuumailmakäsittelyn tulos oli 100-prosenttinen. Torjuntatuloksen lopullinen hyöty riippuu siitä voidaanko kanapunkkien kulkeutuminen kanalaan estää ja kuinka pitkään.

Biologisen torjunnan kokeiden perusteella arvioimme, että Hypoaspis spp. petopunkit ovat lupaavia kanapunkin luontaisia vihollisia. Kevään 2009 kokeissa toisena petona käytetty karvajalkapetopunkki on hollantilaisissa tutkimuksissa osoittautunut myös aikuisten kanapunkkien saalistajaksi (Lesna ym. 2009). Omien kokeidemme perusteella arvioimme, että karvajalkapetopunkki saattaa olla harsosääskipetopunkkia tehokkaampi kanapunkin peto niissä olosuhteissa, jotka kanalassa vallitsivat. Petopunkkien tuotantomenetelmä on jo olemassa, seuraavaksi tulisi paneutua menetelmän käytännön sovelluksen kehittämiseen.

Kanapunkin torjunta ei voi perustua pelkästään yhteen menetelmään. Tärkeää on estää mahdollisuuksien mukaan ulkopuolista saastuntaa, tarkkailla punkkien esiintymistä säännöllisesti ja yhdistää torjuntakokonaisuus tilanteen mukaan puhdistuskäsittelyjen, kemiallisten käsittelyjen ja mahdollisesti biologisen torjunnan tai kasviperäisten valmisteiden vaihtoehdoista. 


\section{Kirjallisuus}

Abdel-Ghaffar, F., Sobhy, H.M., Al-Quraishy, S., Semmler, M. 2008. Field study on the efficacy of an extract of neem seed (Mite-Stop ${ }^{\circledR}$ ) against the red mite Dermanyssus gallinae naturally infecting poultry in Egypt. Parasitology Research 103: 481-485.

Evira. 2009. www.evira.fi/portal/fi/elaimet_ja_terveys/l__ kitseminen/laakeluettelot/

MITEeHEN. 2009. www.ncl.ac.uk/afrd/research/project/1783

Lesna, I., Wolfs, P., Faraji, F., Roy, L., Komdeur, J., Sabelis, M.W. 2009. Candidate predators for biological control of the poultry red mite Dermanyssus gallinae. Experimental and Applied Acarology 48: 63-80.

Maurer, V., Perler, E., Heckendorn, F. 2009. In vitro efficacies of oils, silicas and plant preparations against the poultry red mite Dermanyssus gallinae. Experimental and Applied Acarology 48: 31-41.

Nordenfors, H. Chirico, J. 2001. Evaluation of a Sampling Trap for Dermanyssus gallinae (Acari: Dermanyssidae). Journal of Economic Entomology 94: 1617-1621.

Roy, L., Chauve, C., Delaporte, J., Inizan, G., Buronfosse, T. 2009. Exploration of the susceptibility of AChE from the poultry red mite Dermanyssus gallinae (Acari: Mesostigmata) to organophosphates in field isolates from France. Experimental and Applied Acarology 48: 19-30.

Sparagano, O., Aleksandar Pavlicevic, A., Murano, T., Camarda, A., Sahibi, H., Kilpinen, O., Mul, M., van Emous, R., le Bouquin, S., Hoel, K., Cafiero, M.A. 2009. Prevalence and key figures for the poultry red mite Dermanyssus gallinae infections in poultry farm systems. Experimental and Applied Acarology 48: 3-10.

Tuovinen T. 2008. Predatory arthropods as biocontrol agents of Dermanyssus gallinae? In: BSP Spring, trypanosomiasis/leishmaniasis \& malaria meetings. Newcastle, UK, March 30 - April 2. Abstract booklet: 170 .

Tuovinen, T., Lindqvist, B. 2007. Kanapunkki vaatii huomiota, ongelma herättänyt tutkijat laajasti. Suomen siipikarja 89, 4/2007: 20-21.

Tuovinen, T., Lindqvist, B., Valkonen, E., Valaja, J. 2008. Foksiimi tehoaa kanapunkkiin. Suomen siipikarja 90, 2/2008: 24-25.

Tuovinen, T., Juvonen, S., Lindqvist, B. 2009. Kanapunkin biologinen torjunta: ensimmäisiä koetuloksia. Suomen siipikarja 91, 4/2009: 38-39.

Valiente Moro, C., Chauve, C., Zenner, L. 2007. Experimental infection of Salmonella Enteritidis by the poultry red mite, Dermanyssus gallinae. Veterinary Parasitology 146: 329-336. 